\title{
Cultural Variability, Viability and Longevity of Teliospores of Sorosporium paspali-thunbergii in Kodo Millet
}

\author{
Avneesh Kumar Gupta ${ }^{1}$, Abhilasha Shrivastava ${ }^{3}$ and A. K. Jain ${ }^{2}$ \\ ${ }^{1}$ APS University, Rewa 486001, India \\ ${ }^{2}$ Department of Plant Pathology, JNKVV, College of Agriculture Rewa 486001, India \\ ${ }^{3}$ Government Model Science College, Rewa 486001, India \\ *Corresponding author
}

\section{A B S T R A C T}

\begin{tabular}{|l|}
\hline Ke y w or d s \\
Sorosporium \\
Paspali thunbergii, \\
Kodo millet, \\
Cultural variability, \\
Viability and \\
longevity
\end{tabular}

The teliospores of Sorosporium paspali-thunbergii were observed in spore balls of 17-34 x 42-57 $\mu$. The individual teliospores are globose, sub-globose, angular in shape and yellowish brown to dark brown in colour. The size of teliospore ranged 6-13 x 4-19 $\mu$. Maximum teliospore germination was observed in $2 \%$ glucose solution over $1 \%$ glucose solution and tap water. Maximum radial growth was observed in Potato Dextrose Agar medium followed by Oat Meal Agar medium, Corn Meal Agar medium and Czapek's dox Agar medium. Potato Dextrose Agar medium produced white mycelial colony, submerged and regular fast growth and no pigmentation. White to yellow colony, Sub merged, regular moderate growth and no pigmentation were observed in Oat meal agar medium. Light pink pigmentation, white to light pink mycelial colony and cottony, regular moderate growth were observed in Czapek's dox Agar medium. In Corn meal agar medium was recorded off white colour mycelial colony, cottony, regular moderate growth and no pigmentation. Storage medium and storage period were also observed to influence the viability of teliospores. Highest germination was recorded in teliospores stored in paper bags at $4^{0} \mathrm{C}$. Reduction in longevity of teliospores ranged from 24.6 to $44.6 \%$ in different storage medium over a period of 30 to 105 days.

\section{Introduction}

Kodo millet (Paspalum scrobiculatum L.) is a small grain cereal indigenous to India (De wet et al., 1983) belonging to family Poaceae (Gamineae) and is extensively cultivated in tribal and hilly areas without any or low input by tribal and poor farmers for their consumption. The area of the kodo millet under cultivation is declining, but kodo millet still contributes to the regional food security of the dry and marginal lands, where major kharif crops fail to yield. The crops is cultivated is about 224 thousands hectares in India with productivity of $312 \mathrm{~kg} \mathrm{kgha}{ }^{-1}$ (Anon, 2011). Among the biotic stresses particularly diseases, head smut caused by Sorosporium paspli-thunbergii (Henn.) Ito (Sorosporium paspali thunbergii (Henn.) Vanky) is an important fungal disease and is 
endemic in all the states of the country. The pathogen is externally seed borne in nature however infection may also take place through soil borne inoculum that can reduce production in terms of grain yield. Head smut was first report from Queensland, Australia (McAlpine, 1910). Later on, the disease was reported in India by Butler (1918) and China by Teng (1947). In Madhya Pradesh, the disease was reported first time from Dindori and Jabalpur by Mishra et al., 1976. Viswanath (1992) reported 30 to $40 \%$ loss in grain yield, whereas Jain and Yadava (1997) estimated a loss of 13.15 to $32.98 \%$ at the disease incidence of 13.15 to $40.15 \%$ in different varieties of kodo millet. The symptom appears in the crop at flowering stage and affected panicles are completely transformed into a long sorus which contains black powdery spore masses. Management of the disease through growing resistant varieties is the cheapest and best way, though few fungicides were found very effective in Vitro and in Vivo. Few released, pre-released and landraces of kodo millet resistant to head smut were reported.

\section{Materials and Methods}

To study the morphological characteristics, teliospores of the Sorosporium paspali thunbergii were collected from the freshly harvested smut sorus and measured the colour, size and shape of spore balls and teliospores under compound microscope in the different magnification (x) of $10 \mathrm{x} 40$.

For cultural characteristics studied, teliospores were collected from the freshly harvested smut samples. In this study we used four different culture media to know the better mycelial growth measured through the radial growth in $\mathrm{mm}$. Sterilized teliospores of Sorosporium paspali thunbergii were placed at the centre of $85 \mathrm{~mm}$ petriplates containing $15 \mathrm{ml}$. test media. All the plates were incubated at $28^{\circ} \mathrm{C}$ and measured the radial growth. The radial growth was measured in

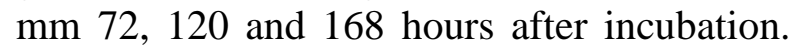
The culture characters of the pathogen (Colony colour, growth pattern etc.) were recorded by visual observation. Pigmentation was also recorded by colour production from the back side of the culture plate.

Different culture media used in this study were given in Table 1 .

For spore morphology and measurement studied, teliospores of the Sorosporium paspali thunbergii were collected from the freshly harvested smut sorus and measured the size using ocular micrometer and shape of spore balls and teliospores under compound microscope in the magnification (x) of $15 \mathrm{x}$ 40 .

For spore germination studies, teliospores stored along with host were used for germination studies in different nutrients. The aqueous suspension of teliospores was prepared in tap water, $1 \%$ glucose and $2 \%$ glucose solution. Then a drop of the suspension was placed on the cavity slides in 4 replications. The cavity slides were kept in moist chamber prepared in petri plates and incubated at room temperature for 24 hours. Germination of teliospores was recorded under compound microscope and percent germination was calculated using following

Formula:

Percent germination $=$

Number of spore germinated $\mathrm{x} 100$

Total no. of spores observed

For the teliospore longevity study of the head smut pathogen stored in different storage medium viz. paper bags and polythene bags at 
$4^{0} \mathrm{C}$ in the refrigerator and at room temperature was studied at 15 days interval in cavity slides in 4 replications. The teliospore germination was recorded and germination percentage was calculated.

Formula:

Number of spore germinated

Percent germination=------------------------ x100

Total no. of spores observed

\section{Results and Discussion}

The results indicate on spore ball, size, colour and measurement of teliospores are presented in Table 1. Teliospores of Sorosporium paspali-thunbergii remains in loose ball like masses and disintegrated into individual spores in the water with little pressure. Size of spore ball ranged 17-34 x 42-57 $\mu$ and individual teliospores were globose, subglobose and angular in shape, measured 6-13 x 4-19 $\mu$. Teliospores were yellowish brown to dark brown in colour with thick smooth wall (Plate 1).

The results on germination of teliospores were taken from smut sorus enclosed in boot leaf with host and germination as studied in tap water, $1 \%$ glucose solution and $2 \%$ glucose solution. The results of teliospore germination are presented in table 2 . Significant differences in teliospore germination were observed in various treatments. Maximum mean teliospore germination was recorded in $2 \%$ glucose solution $(58.0 \%)$ followed by $1 \%$ glucose solution $(53.4 \%)$ and tape water $(50.3 \%)$. Maximum teliospore germination was recorded in $2 \%$ glucose solution over $1 \%$ glucose and tape water as also reported by Ahmed (1991), Nemade (2012) and Nemade at el. (2015b). Zundel (1953), Ahmad (1991), Shivas (2010), Nemade (2012) and Nemade at el. (2015b) also reported similar type of observations, which confirms the present findings.
The results on different cultural characteristics of Sorosporium pasplithunbergii were studied in four culture media are presented in Table 3. The colony colour, growth pattern and pigmentation were found diverse in all culture media. Sorosporium paspli-thunbergii produced submerged, regular fast growing white colony without pigmentation in Potato Dextrose Agar (PDA). In Oat Meal Agar (OMA) media, fungus produced white to light yellow colony, submerged, regular moderate growing and without pigmentation. White to light pink colony, cottony, regular moderate growth with light pink pigmentation were recorded in Czapek's dox Agar medium whereas off white colony, cottony, regular moderate growth without pigmentation was found in Corn Meal Agar (CMA) (Plate 2 and 3).

The radial growth of Sorosporium pasplithunbergii was recorded in four culture media at different time intervals i.e. 72, 120 and 168 hrs after incubation (Table 4). Significant differences in radial growth recorded in different culture media. Radial growth of the fungus ranged 35.3 to $42.7 \mathrm{~mm}, 48.6$ to 62.0 $\mathrm{mm}$ and 68.7 to $89.3 \mathrm{~mm}$ after 72,120 and 168 hours of incubation, respectively. Maximum mycelial growth of fungus was recorded in Potato Dextrose Agar $(89.3 \mathrm{~mm})$ followed by Oat Meal Agar (88.0 mm), Corn Meal Agar $(88.0 \mathrm{~mm})$ and Czapek's dox Agar $(68.7 \mathrm{~mm})$ after incubation of $168 \mathrm{hrs}$. The radial growth of Sorosporium pasplithunbergii in Potato Dextrose Agar, Oat Meal Agar and Corn Meal Agar medium was at par. Ahmed (1991) and Nemade (2012) also reported maximum radial growth in Potato Dextrose Agar medium followed by followed by Czapak’s Ager medium.

The results on viability and longevity, germination of teliospores were studied in at different storage medium i.e. paper bag, polythen bags and different time of intervals. Data of teliospore germination in two storage 
medium and six storage periods were presented in Table 5 and Fig. 6. All the treatments were found to be significant. Teliospore germination was recorded $61.5 \%$ after 30 days of storage in paper bags at $4^{0} \mathrm{C}$, which gradually decreased and only $46.4 \%$ germination was recorded after 105 days of storage. Similarly, $59.8 \%$ teliospore germination was recorded after 30 days of storage and after 105 days of storage only $40.7 \%$ germination was noted. In polythene bag storage at $4^{0} \mathrm{C}$, spore germination was $47.1 \%$ and $33.5 \%$ after 30 and 105 days of storage, respectively. Teliospore stored in polythene bags at room temperature, germination percentage recorded $55.6 \%$ after 30 days and $30.8 \%$ after 105 days of storage.

Table.1 Different culture media used in this study

(A) Potato Dextrose Agar (PDA) medium

\begin{tabular}{|l|l|}
\hline Composition & Quantities \\
\hline Potato (peeled and sliced) & $\mathbf{2 0 0} \mathrm{g}$ \\
\hline Dextrose & $\mathbf{2 0} \mathrm{g}$ \\
\hline Agar-agar & $\mathbf{2 0} \mathrm{g}$ \\
\hline Distilled water & $\mathbf{1 0 0 0} \mathrm{ml}$ \\
\hline
\end{tabular}

(B) Czapek Agar (CA) Medium

\begin{tabular}{|l|l|}
\hline Composition & Quantities \\
\hline Sucrose & $30 \mathrm{~g}$ \\
\hline NaNO3 & $\mathbf{3 g}$ \\
\hline K2HPO4·H2O & $1 \mathrm{~g}$ \\
\hline MgSO4·7H2O & $\mathbf{0 . 5} \mathrm{g}$ \\
\hline KCl & $\mathbf{0 . 5} \mathrm{g}$ \\
\hline FeSO4 & $\mathbf{0 . 0 1} \mathrm{g}$ \\
\hline Agar & $\mathbf{1 5} \mathrm{g}$ \\
\hline H2O(Distilled water) & $1000 \mathrm{ml}$ \\
\hline
\end{tabular}

(C) Oatmeal Agar (OMA) Medium

\begin{tabular}{|l|l|}
\hline Composition & Quantities \\
\hline Oatmeal & $\mathbf{3 0 ~ g}$ \\
\hline Agar-agar & $\mathbf{1 5} \mathbf{~ g}$ \\
\hline Distilled water & $\mathbf{1 0 0 0} \mathbf{~ m l}$ \\
\hline
\end{tabular}

(D) Corn Meal Agar (CMA) Medium

\begin{tabular}{|l|l|}
\hline Composition & Quantities \\
\hline Corn meal & $\mathbf{2 0 0} \mathrm{g}$ \\
\hline Agar-agar & $\mathbf{1 5} \mathrm{g}$ \\
\hline Distilled water & $1000 \mathrm{ml}$ \\
\hline
\end{tabular}


Table.1 Characteristics of Sorosporium paspali-thunbergii

\begin{tabular}{|c|l|l|}
\hline S. No. & \multicolumn{1}{|c|}{ Characteristics } & \multicolumn{1}{c|}{ Colour and measurements } \\
\hline $\mathbf{1}$ & Size of spore bolls * & $17-34 \times 42-57 \mu$ \\
\hline $\mathbf{2}$ & Size of teliospores** & $6-13 \times 4-19 \mu$ \\
\hline $\mathbf{3}$ & Shape of teliospores & Globose, sub-globose and angular \\
\hline $\mathbf{4}$ & Colour of teliospores & Yellowish brown to dark brown \\
\hline *Mean of 30 spore bolls & **Mean of 30 teliospores \\
\hline
\end{tabular}

Table.2 Effect of nutrients on teliospore germination of Sorosporium paspali-thunbergii

\begin{tabular}{|c|c|c|}
\hline S. No. & Treatments & Germination (\%) \\
\hline $\mathbf{T}_{1}$ & Glucose solution (1\%) & $54.2(47.41)^{*}$ \\
\hline $\mathbf{T}_{2}$ & Glucose solution (2\%) & $60.5(51.06)$ \\
\hline \multirow[t]{5}{*}{$\mathbf{T}_{3}$} & Tap water & $50.3(45.17)$ \\
\hline & Mean & $55.0(47.87)$ \\
\hline & SEm & 1.33 \\
\hline & CD (5\%) & 3.70 \\
\hline & $\mathrm{CV}(\%)$ & 4.83 \\
\hline
\end{tabular}

* Figures are arc sin transformed values

Table.3 Cultural characteristics of Sorosporium paspli-thunbergii of kodo millet on different culture medium

\begin{tabular}{|l|l|l|l|l|}
\hline $\begin{array}{l}\text { S. } \\
\text { No. }\end{array}$ & \multicolumn{1}{|c|}{ Medium } & Colony colour & Growth pattern & Pigmentation \\
\hline $\mathbf{1}$ & $\begin{array}{l}\text { Potato Dextrose } \\
\text { Agar }\end{array}$ & White & $\begin{array}{l}\text { Sub merged, } \\
\text { regular fast }\end{array}$ & No pigmentation \\
\hline $\mathbf{2}$ & Oat Meal Agar & White to light yellow & $\begin{array}{l}\text { Sub merged, } \\
\text { regular moderate }\end{array}$ & No pigmentation \\
\hline $\mathbf{3}$ & $\begin{array}{l}\text { Czapek's dox } \\
\text { Agar }\end{array}$ & White to light pink & $\begin{array}{l}\text { Cottony, regular } \\
\text { moderate }\end{array}$ & Light pink \\
\hline $\mathbf{4}$ & Corn Meal Agar & Off white & $\begin{array}{l}\text { Cottony, regular } \\
\text { moderate }\end{array}$ & No pigmentation \\
\hline
\end{tabular}

Table.4 Radial growth of Sorosporium paspli-thunbergii on different culture media

\begin{tabular}{|l|l|c|c|c|}
\hline S. & \multicolumn{1}{|c|}{ Medium } & \multicolumn{3}{|c|}{ Colony diameter (mm) } \\
\cline { 3 - 5 } No. & & $72 \mathrm{hrs}$ & $120 \mathrm{hrs}$ & $168 \mathrm{hrs}$ \\
\hline $\mathbf{1}$ & Potato Dextrose Agar & 42.7 & 62.0 & 89.3 \\
\hline $\mathbf{2}$ & Oat Meal Agar & 35.3 & 57.3 & 88.0 \\
\hline $\mathbf{3}$ & Czapek's dox Agar & 39.3 & 48.6 & 68.7 \\
\hline $\mathbf{4}$ & Corn Meal Agar & 38.7 & 57.3 & 88.0 \\
\hline & CD(P=0.05) & 2.171 & 2.667 & 2.437 \\
\hline
\end{tabular}


Table.4.6 Effect of storage medium and period on teliospore germination of Sorosporium paspali-thunbergii

\begin{tabular}{|c|c|c|c|c|c|c|c|c|c|}
\hline \multirow{2}{*}{$\begin{array}{c}\text { S. } \\
\text { No }\end{array}$} & \multirow[t]{2}{*}{ Storage at different medium } & \multicolumn{7}{|c|}{ Storage at different time intervals (days) } & \multirow{2}{*}{$\begin{array}{l}\text { \% reduction } \\
\text { in teliospore } \\
\text { germination }\end{array}$} \\
\hline & & 30 & 45 & 60 & 75 & 90 & 105 & Mean & \\
\hline 1 & Teliospores in paper bags at $4 \mathrm{C}$ & $\begin{array}{c}61.5 \\
(51.65)^{*}\end{array}$ & $\begin{array}{c}59.5 \\
(50.48)\end{array}$ & $\begin{array}{c}56.8 \\
(48.91)\end{array}$ & $\begin{array}{c}54.7 \\
(47.70)\end{array}$ & $\begin{array}{c}50.5 \\
(45.29)\end{array}$ & $\begin{array}{c}46.4 \\
(42.88)\end{array}$ & $\begin{array}{c}54.9 \\
(47.81)\end{array}$ & 24.6 \\
\hline 2 & Teliospores in paper bags at room temp. & $\begin{array}{c}59.8 \\
(50.65)\end{array}$ & $\begin{array}{c}56.5 \\
(48.73)\end{array}$ & $\begin{array}{c}54.9 \\
(47.81)\end{array}$ & $\begin{array}{c}51.6 \\
(45.92)\end{array}$ & $\begin{array}{c}46.5 \\
(42.99)\end{array}$ & $\begin{array}{c}40.7 \\
(39.64)\end{array}$ & $\begin{array}{c}51.7 \\
(45.97)\end{array}$ & 31.9 \\
\hline 3 & Teliospores in polythene bags at $4 \mathrm{C}$ & $\begin{array}{c}47.1 \\
(43.34)\end{array}$ & $\begin{array}{c}44.3 \\
(41.73)\end{array}$ & $\begin{array}{c}42.5 \\
(40.69)\end{array}$ & $\begin{array}{c}40.4 \\
(39.47)\end{array}$ & $\begin{array}{c}37.4 \\
(37.70) \\
\end{array}$ & $\begin{array}{c}33.5 \\
(35.37)\end{array}$ & $\begin{array}{c}40.9 \\
(39.76)\end{array}$ & 28.9 \\
\hline \multirow[t]{4}{*}{4} & Teliospores in polythene bags at room temp. & $\begin{array}{c}55.6 \\
(48.22)\end{array}$ & $\begin{array}{c}46.4 \\
(42.94)\end{array}$ & $\begin{array}{c}43.5 \\
(41.27)\end{array}$ & $\begin{array}{c}38.2 \\
(38.17)\end{array}$ & $\begin{array}{c}34.7 \\
(36.09)\end{array}$ & $\begin{array}{c}30.8 \\
(33.71)\end{array}$ & $\begin{array}{c}41.5 \\
(40.11)\end{array}$ & 44.6 \\
\hline & Mean & $\begin{array}{c}56.0 \\
(48.45)\end{array}$ & $\begin{array}{c}51.7 \\
(45.97)\end{array}$ & $\begin{array}{c}49.4 \\
(44.66)\end{array}$ & $\begin{array}{c}46.2 \\
(42.82)\end{array}$ & $\begin{array}{c}42.3 \\
(40.57)\end{array}$ & $\begin{array}{c}37.9 \\
(38.00)\end{array}$ & $\begin{array}{c}47.2 \\
(43.39)\end{array}$ & \\
\hline & SEm \pm & 0.301 & 0.392 & 0.386 & 0.334 & 0.330 & 0.343 & & \\
\hline & CD $(5 \%)$ & 0.98 & 1.29 & 1.30 & 1.08 & 1.06 & 1.13 & & \\
\hline
\end{tabular}

* Figures in parentheses are arc sin transformed values 


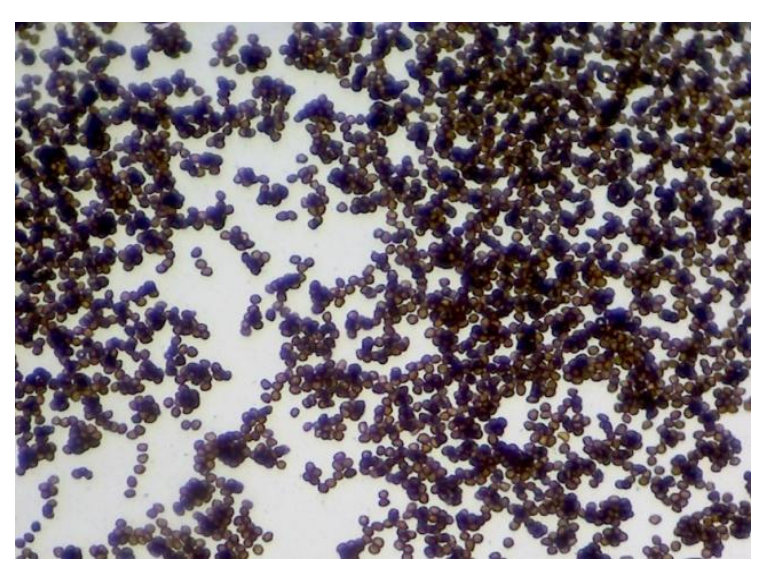

Non teliospore germination at $100 \mathrm{X}$ magnification

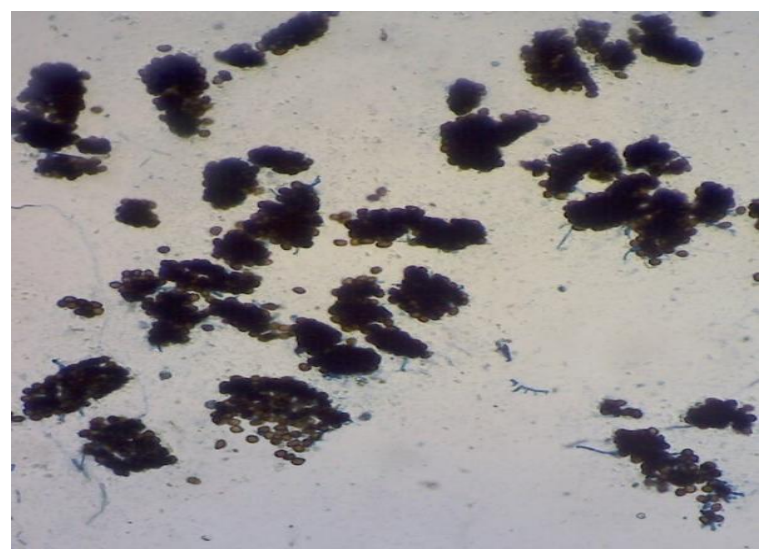

Teliospore germination at 100 x magnification

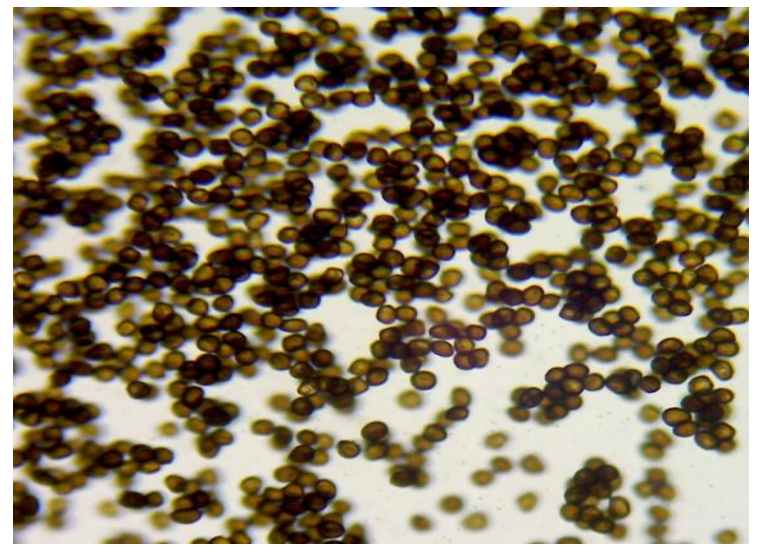

Nonteliospore germination at $200 \mathrm{X}$ magnification

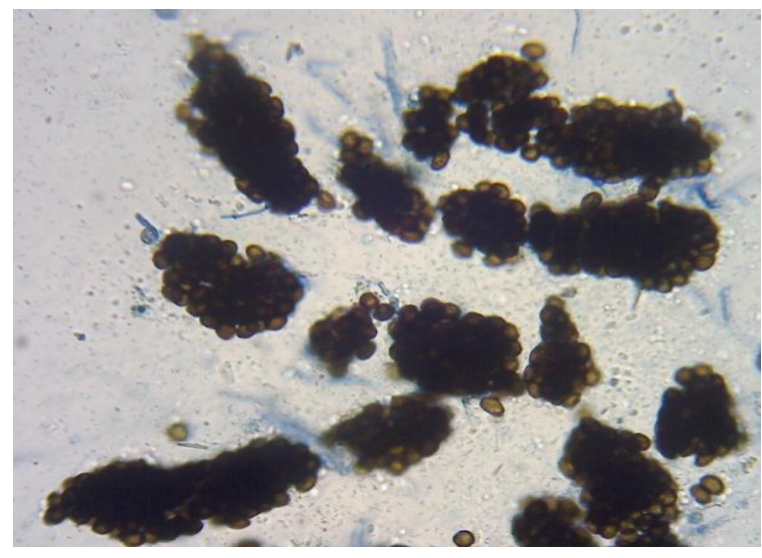

Teliospore germination at $200 \mathrm{X}$ magnification

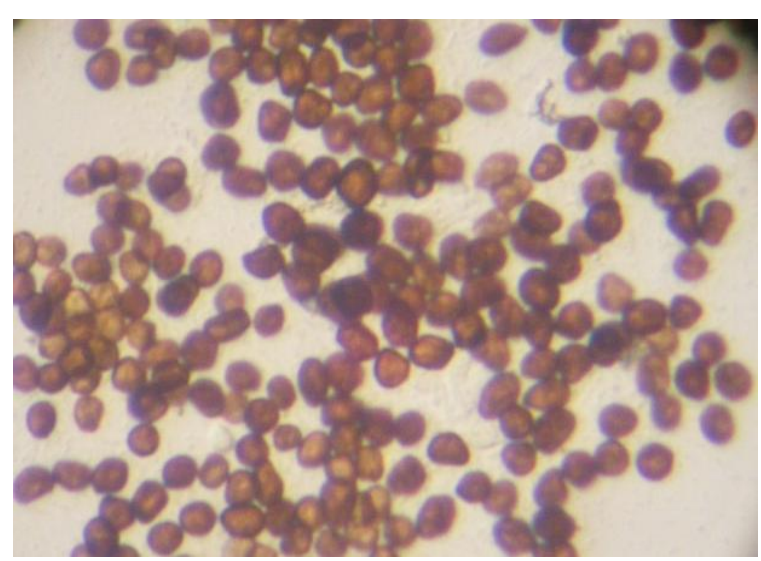

Non teliospore germination at $400 \times$ magnification

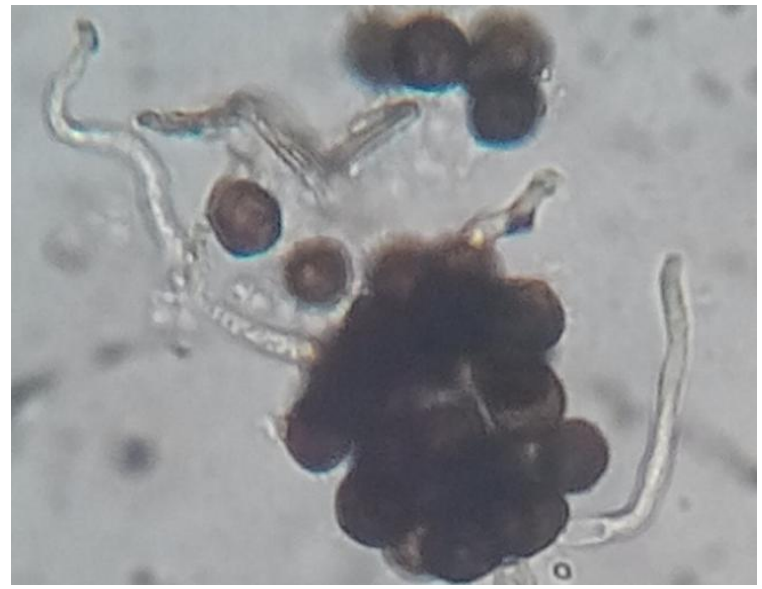

Teliospore germination at $400 \mathrm{x}$ magnification

Plate 1.Non germinated and germinated teliospores of Sorosporiumpaspalithunbergiiof kodo millet. 


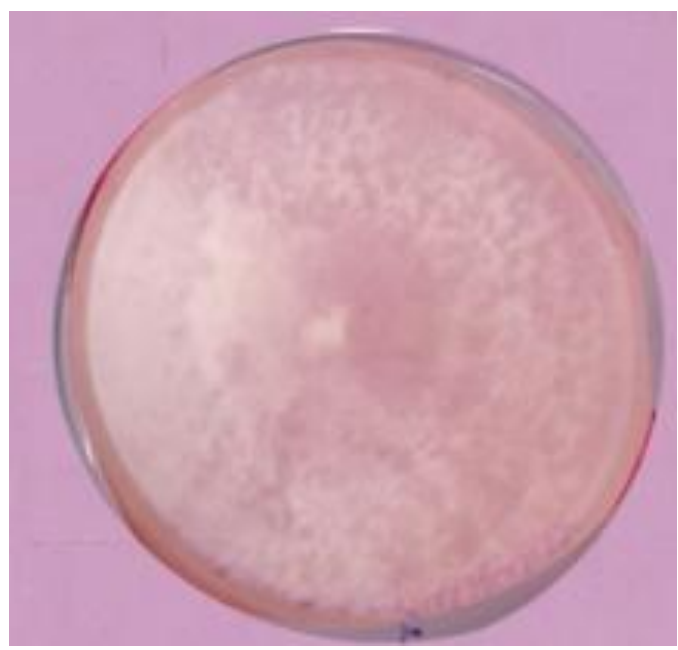

B- Potato Dextrose Agar

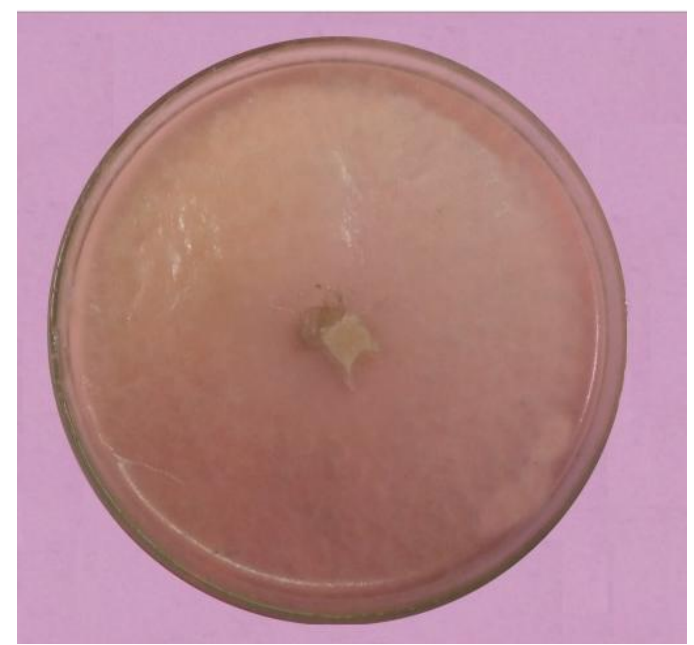

C - Corn Meal agar

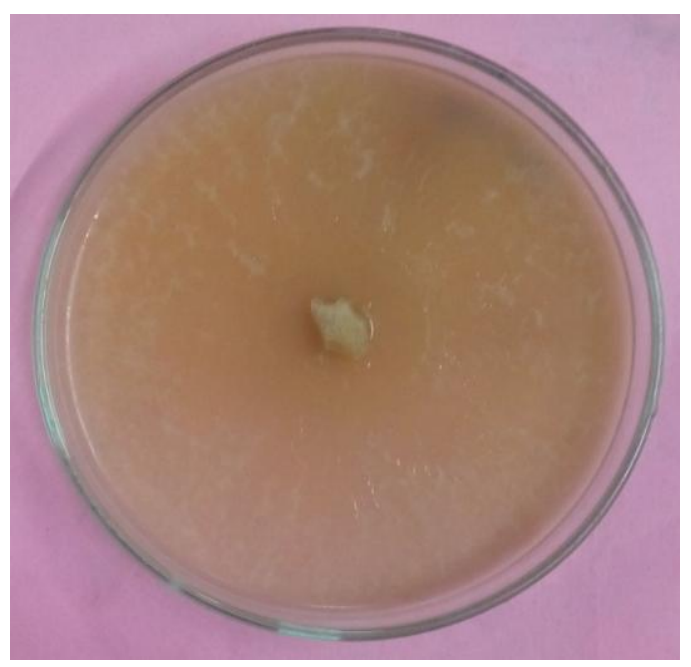

A- Oat Meal Agar

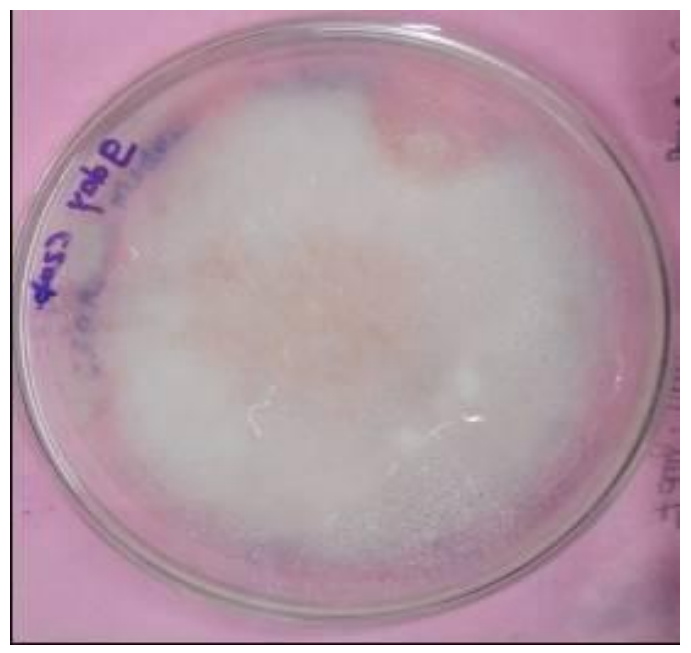

D- Czapek Dox agar

\section{A- Front view of culture plates}

Plate.2 Radial growth of Sorosporium paspali thunbergii in different medium 


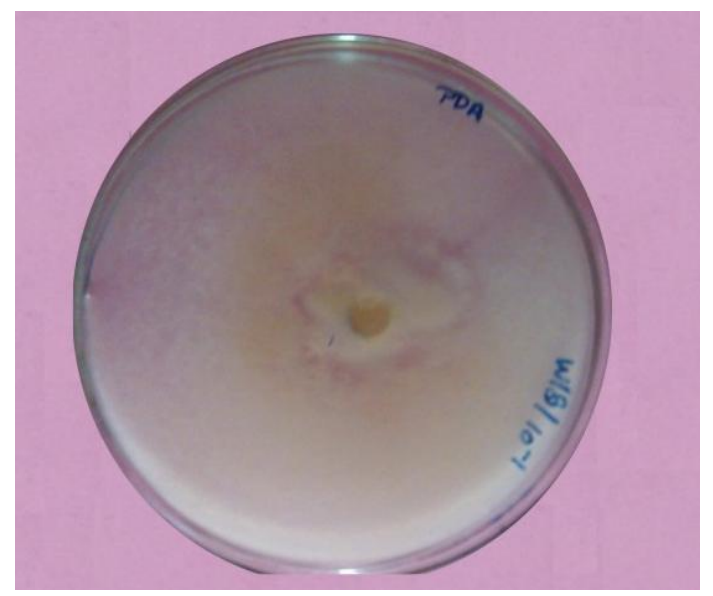

A- Potato Dextrose agar

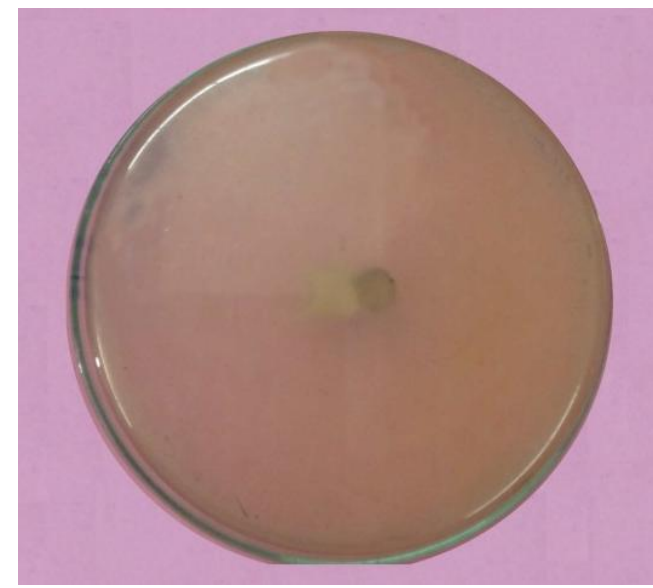

C- Corn Meal Agar

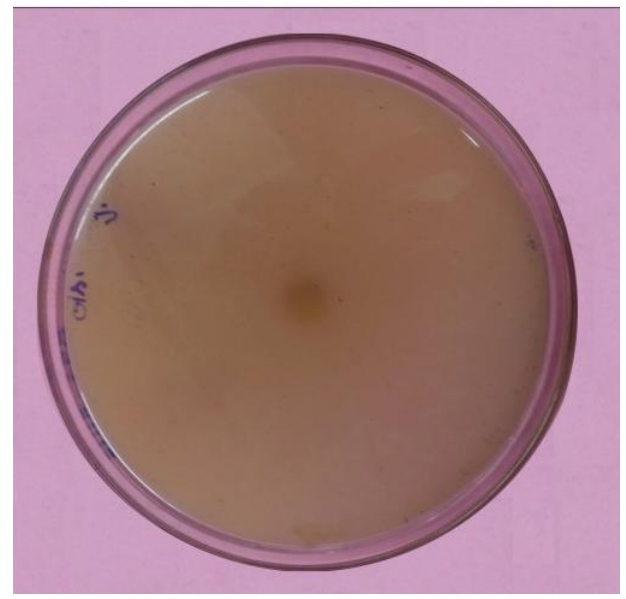

B - Oat Meal Agar

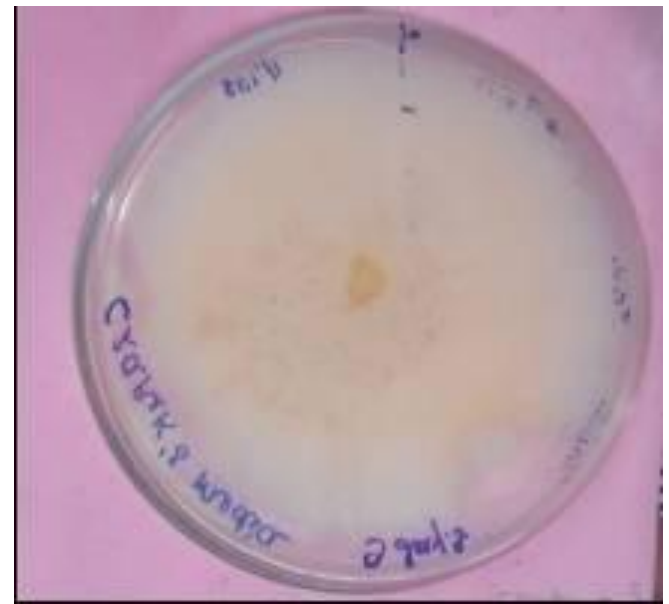

D- Cazpek Dox Agar

\section{A- Back view of culture plates}

Plate.3 Radial growth of Sorosporium paspali thunbergii in different medium

Mean percent germination varied from 40.9 to $54.9 \%$ in different storage medium was highest in teliospores stored in paper bags at $4^{\circ} \mathrm{C}(54.9 \%)$ over a period of 30 to 105 days, where as lowest was recorded in teliospores stored in polythene bags at $4^{\circ} \mathrm{C}(40.9 \%)$ over a period of 30 to 105 days. Maximum percent reduction in teliospore germination was recorded in teliospore stored in polythene bags at room temperature $(44.6 \%)$ over a period of 30 to 105 days, where as minimum percent reduction was recorded in teliospore stored in paper bags at $4^{\circ} \mathrm{C}(24.6 \%)$ over a period of 30 to 105 days. Teliospore longevity of Sorosporium paspali thunbergii has been reported seven months by Ahmed (1991) that confirms the reduction of teliospores germination with storage period. Nemade (2012) also reported similar type of findings.

In conclusions, teliospores remains in spore balls, measured 17-34 x 42-57 $\mu$ and individual teliospores are globose to subglobose, angular and yellowish brown to dark 
brown in colour. Size of teliospore varied from 6-13 x 4-19 $\mu$. Maximum radial growth of Sorossporium pappali thunbergii was in Potato Dextrose Agar medium after incubation of 168. White mycelial colony, submerged and regular fast growth and no pigmentation produced by the PDA medium. Viability of teliospores was maximum in $2 \%$ glucose solution. Maximum viability was found in teliospores stored in paper bags at 4 C. Longevity of teliospores reduced significantly from 24.6 to $44.6 \%$ with storage period from 30 to 105 days.

\section{References}

Ahmed, N. N. (1991). Biology of smut fungi of the minor millets Paspalum scrobiculatum L. and Echinochloa frumentacea (Robx.) Link in Karnataka. M.Sc.(Agri.) Thesis, University of Agricultural Sciences, Bangalore, India. pp 1-91.

Annonymous (2011). Co-ordinators Review. Paper presented in Annual Workshop of AICRP on Small Millets, held at OUAT, Bhubaneshwar (Odisha) on April, 23-25, 2011.

Butler, E. J. (1918). Fungi and diseases of plants. Thacker Spink and Co., Calcutta. pp VI + 547 .

De Wet, J. M. J., Prasada Rao, K. E., Mengesha, M. H. and Brink, D. E., (1983). Diversity in Kodo Millet, Paspalum scrobiculatum. Econ. Bot., 37 (2): 159-163.

Jain, A. K. and Yadava, H. S. (1997). Recent approaches in disease management of Small Millets. Proc. Nat. Semi. on
Small Millets - Current Reseach Trends and Future Priorities as Food, Feed and in Processing for Value Addition, held at TNAU, Coimbatore (T.N.) from 23-24 April, 1997. pp 31-33.

McAlpine, D. (1910). The smuts of Australia, Melborne. pp 285

Mishra, R. P., Pall, B. S. and Nema, K.G. (1976). Ustilaginales of Jabalpur, Madhya Pradesh II. JNKVV Res. Jour. 10(2): 189.

Nemade, J. (2012). Studies on vulnerability of kodo millet genotypes to head smut caused by Sorosporium paspali thunbergii (Henn) Ito. M.Sc. (Ag) Thesis JKKVV, Jabalpur (M.P)

Nemade, J., Jain A. K. and Kumar, Ashish (2015b). Studies on symptoms and morphological characteristics of Sorosporium paspali thunbergii (Henn.) Ito causing head smut in kodo millet. Ann. Pl. Prot. Sci. 23(1):106-110.

Shivas, Roger (2010). Paspalum smut (Sporisorium paspali-thunbergii). Updated on 13.10.2010. http://www.padil.gov.au:80/aussmut/Pest/Main/140050.

Teng, S.C. (1947). Addition to myxomycetes and the carpomycetes of China. Bot. Bull. Acad. Sinica. pp.25-44 (RAM 26:421).

Vishwanath, S. (1992). Management of biotic factors (diseases). In $6^{\text {th }}$ Annual Small Millets Workshop at B.A.U. Ranchi. Kanke from $30^{\text {th }}$ April to $2^{\text {nd }}$ May. 1992.

Zundel, G. L. (1953). The Ustilanginales of the world. School of Agriculture, State College. Pennsylvania. pp. 69.

\section{How to cite this article:}

Avneesh Kumar Gupta, Abhilasha Shrivastava and Jain, A. K. 2020. Cultural Variability, Viability and Longevity of Teliospores of Sorosporium paspali-thunbergii in Kodo Millet. Int.J.Curr.Microbiol.App.Sci. 9(03): 1923-1932. doi: https://doi.org/10.20546/ijcmas.2020.903.224 